\title{
Vertical Lifting of Ionization during Geomagnetic Storms from Satellite Measurements of Ion Composition
}

\author{
M.K. Goel, ${ }^{*}$ B.C.N. RaO, ${ }^{*}$ S. Chandra, ${ }^{* *}$ and E.J. MAIER ${ }^{* *}$ \\ *Radio Science Division, National Physical Laboratory, \\ New Delhi, India \\ **NASA/Goddard Space Flight Center, Greenbelt, Maryland, U.S.A.
}

(Received March 12, 1977)

\begin{abstract}
Magnetic storm phenomena at low latitudes are discussed based on the ion composition $\left(\mathrm{O}^{+}, \mathrm{H}^{+}, \mathrm{He}^{+}\right)$and electron and ion temperature measurements from the OGO-4 and the ISIS-2 satellites.

For the moderately severe storms considered, the effects of changes in the neutral composition and in the neutral and plasma temperatures are discussed and it is shown that these changes would not produce the observed $\mathrm{O}^{+}$increase during storms at low latitudes. It is suggested that the observed increase in $\mathrm{O}^{+}$in the topside region is a manifestation of the vertical lifting of ionization of the $F$-layer. The argument in favour of the vertical lifting is further substantiated by the observed changes in the $F$-region critical frequency and the height parameters.
\end{abstract}

\section{Introduction}

The storm time behaviour of the ionosphere is known to be very complex and the changes observed are found to be dependent on the phase of the storm and also on the location (ОвауASHI, 1964; Rishbeth, 1968). While most of the observations pertain to the changes in the peak density $N_{m} F_{2}$ and peak height $h_{m} F_{2}$ of the $F_{2}$-region there are some studies made of the bottomside and topside profiles (Matsushita, 1963; Somayajulu, 1963; Bauer and Krishnamurty, 1968). The most important of the several mechanisms invoked to explain the storm time behaviour are changes in (i) atmospheric temperature, (ii) chemical composition, (iii) neutral air winds, and (iv) electrodynamic drifts (CHANDRA and Herman, 1969; Richmond and Matsushita, 1975; Ruster and King, 1976; Rishbeth, 1975). Although no single mechanism can account for all the observed changes, it is quite likely that every one of them will contribute to some extent at some place or phase of the storm. In recent years attempts have been made to obtain direct evidence for these causative mechanisms. For example, satellite measurements have provided evidence for atmospheric heating 
during storms (JACCHIA et al., 1967; BLAMONT and Luton, 1972). Incoherent scatter measurements have provided evidence for an increase in electron and ion temperatures during storms (Evans, 1970) and for increased upward ion velocity during certain times of the storm (EvANs, 1973). Recent satellite measurements have also shown the changes in neutral composition, i.e., a decrease in atomic oxygen and an increase in molecular nitrogen (TAEUsCH et al., 1971; Prolss and Von Zahn, 1974; Chandra and Spencer, 1976).

In this report we present certain observations on changes in the ion composition in the topside ionosphere in the low latitude region which provide an indirect evidence for vertical lifting of ionization during storms. These observations are made with retarding potential analysers aboard satellites OGO-4 and ISIS-2 during two storms in Sept. 1967 when the $K_{p}$ value was $4^{+}$and $A_{p}$ was 29 as compared to the prestorm values of 1 and 4, respectively; and June 1972 when the $K_{p}$ value was $7^{+}$and $A_{p}$ was 62 as compared to the prestorm values of 3 and 10, respectively. OGO-4 measurements relate to observations in the altitude range of $860-900 \mathrm{~km}$ during Sept. 1967, while ISIS-2 measurements relate to observations at the altitude of $1,400 \mathrm{~km}$. Although latitudinal and

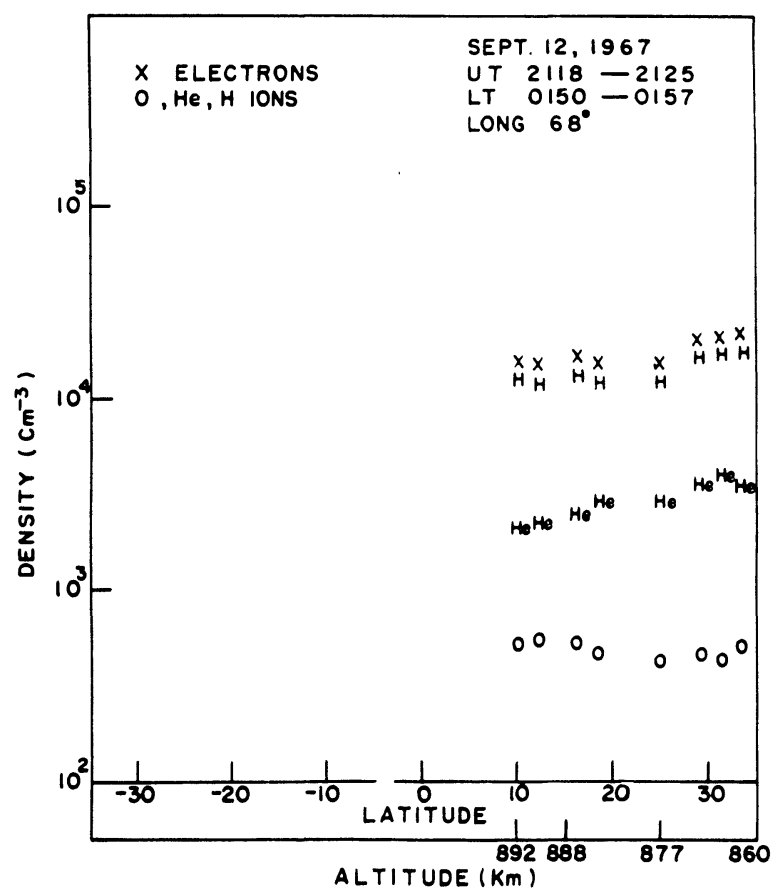

Fig. 1a. Ion density distribution from OGO-4 on a prestorm night i.e., 12 Sept. 1967 . The $A_{p}$ value on this day was 4 and 3-hourly $K_{p}$ corresponding to this pass was 1 . 
altitudinal effects are intermingled in these data, it is still possible to look at the gross features and identify the major changes that occur during storms.

\section{Observations in the Changes of Ion Composition}

Figure 1a shows the ion density distribution on the prestorm night of 12 Sept. 1967 which was very quiet. The data refer to local midnight at 01-02 hr in the $60^{\circ} \mathrm{E}$ longitude $0-35^{\circ}$ latitude region. It may be seen that under quiet conditions the $\mathrm{H}^{+}$ions are predominant at these altitudes of $860-880 \mathrm{~km}$; the transition from $\mathrm{O}^{+}$to $\mathrm{H}^{+}$must have occurred at a much lower altitude than $860 \mathrm{~km}$ since the $\mathrm{H}^{+}$densities observed are more than an order of magnitude higher than $\mathrm{O}^{+}$; the $\mathrm{He}^{+}$ions are also significant being more than $\mathrm{O}^{+}$ions.

Figure $1 \mathrm{~b}$ shows the storm time observations on 13 Sept. 1967 at $01-02 \mathrm{hr}$ local time in the same $60^{\circ}$ longitude zone as in Fig. 1a. These storm observations are made approximately $17 \mathrm{hr}$ after the sudden commencement of the storm. They clearly show that $\mathrm{O}^{+}$ion density has increased by an order of

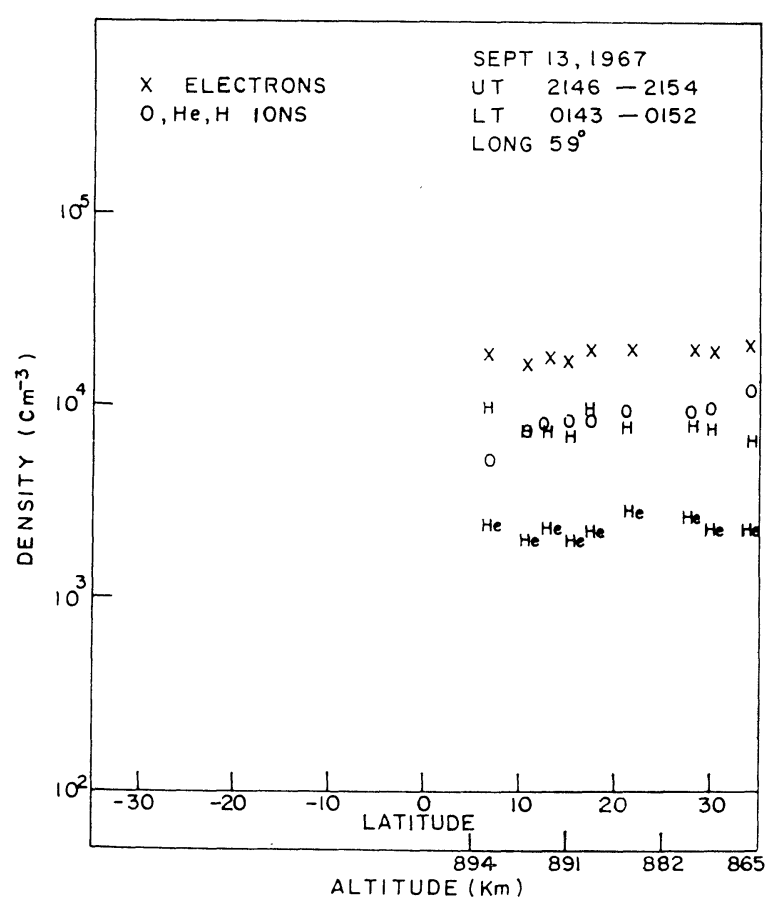

Fig. 1b. Ion density distribution from OGO-4 on storm night i.e., 13 Sept. 1967. The $A_{p}$ value on this day was 29 and 3-hourly $K_{p}$ corresponding to this pass was $4^{+}$. 


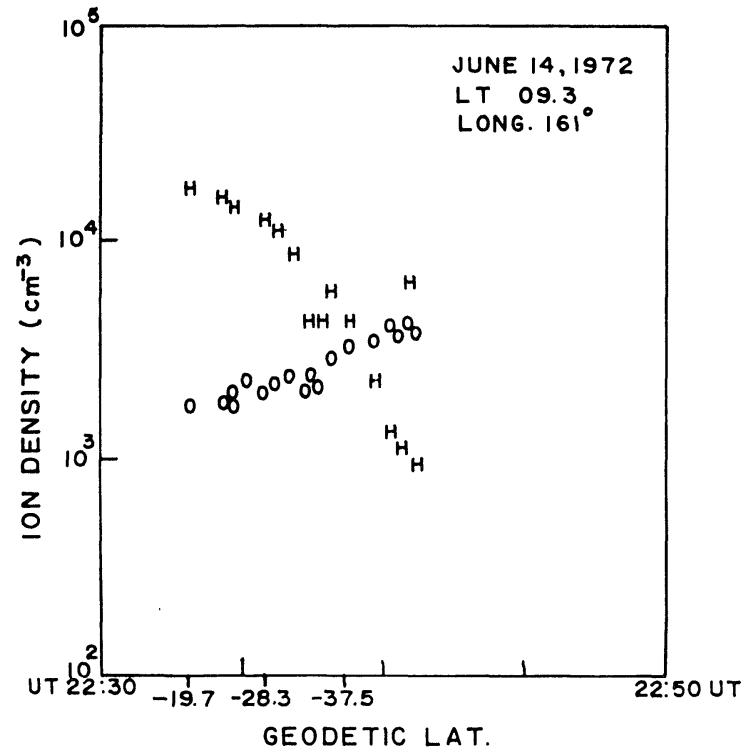

Fig. 2a. Ion density distribution from ISIS-2 on quiet day i.e., 14 June 1972. The $A_{p}$ value on this day was 10 and 3 -hourly $K_{p}$ corresponding to this pass was 3 . $T_{i}=3,500^{\circ} \mathrm{K}$ and $T_{e}=3,900^{\circ} \mathrm{K}$.

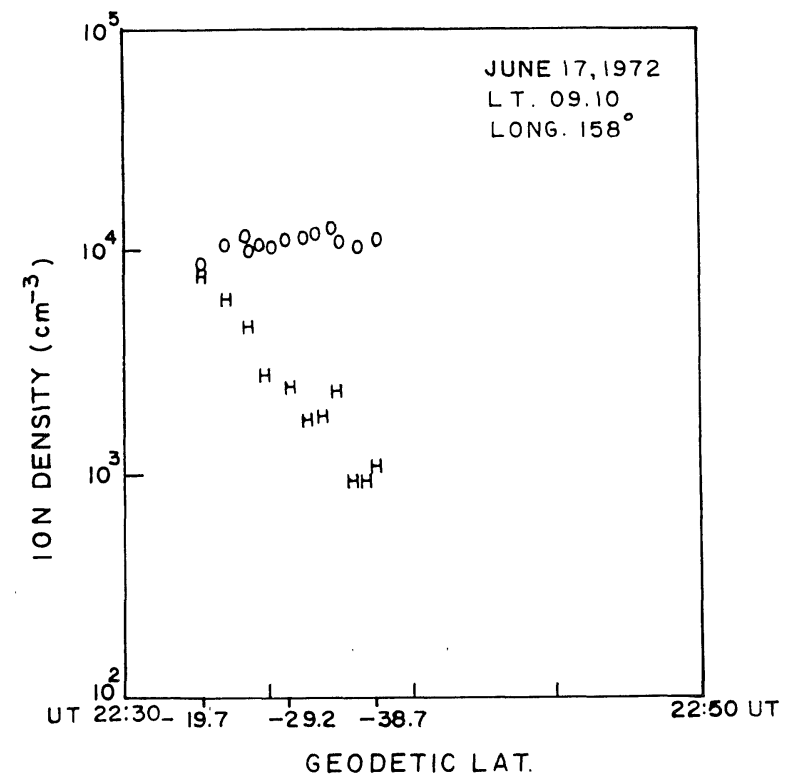

Fig. 2b. Ion density distribution from ISIS-2 on storm day i.e., 17 June 1972. The $A_{p}$ value on this day was 62 and 3-hourly $K_{p}$ corresponding to this pass was $7^{+} . T_{i}=2,500^{\circ} \mathrm{K}$ and $T_{e}=3,200^{\circ} \mathrm{K}$. 
magnitude while both $\mathrm{H}^{+}$and $\mathrm{He}^{+}$are very little affected. The $\mathrm{O}^{+}$and $\mathrm{H}^{+}$ densities are about $9 \times 10^{3} \mathrm{~cm}^{-3}$ while $\mathrm{He}^{+}$is about $2 \times 10^{3} \mathrm{~cm}^{-3}$.

Figures $2 \mathrm{a}$ and $2 \mathrm{~b}$ show the ion density distributions on quiet (14th) and storm (17th) days in June 1972. They are obtained at about $09 \mathrm{hr}$ local time and in the $160^{\circ}$ longitude and $-20^{\circ}$ to $-40^{\circ}$ latitude region. On the quiet day the $\mathrm{O}^{+}$density lies between $0.2 \times 10^{4}$ and $0.4 \times 10^{4} \mathrm{~cm}^{-3}$ while on the disturbed day it lies between $0.9 \times 10^{4}$ to $1.2 \times 10^{4} \mathrm{~cm}^{-3}$ in the same region. It can be seen that $\mathrm{O}^{+}$has increased by a factor of 3 to 4 . At the same time there is a decrease of $\mathrm{H}^{+}$density by a factor of 2 in this region.

\section{Discussion}

The storm related changes in ion composition observed at low latitudes resemble those observed at mid latitudes as discussed by CHANDRA et al. (1971) and MAIER et al. (1975). The mid-latitude phenomena have been attributed to the changes in neutral composition and the increase in neutral and plasma temperatures. This explanation does not seem to be valid for low latitudes in spite of apparent similarities in composition changes of the two regions. During the September storm, the electron and ion temperatures $\left(T_{e}\right.$ and $\left.T_{i}\right)$ did not change significantly compared to prestorm values. Both before and during the storm (Figs. 1a and 1b) $T_{i}$ was in the range of $1,100-1,300^{\circ} \mathrm{K}$ and $T_{e}$ in the range of $1,300-1,500^{\circ} \mathrm{K}$. During the June storm both $T_{e}$ and $T_{i}$ actually decreased at $1,400 \mathrm{~km}$ compared to prestorm values. The ion temperatures on June 17 (Fig. 2b) was above $2,500^{\circ} \mathrm{K}$. This value is about $1,000^{\circ} \mathrm{K}$ less than the values on June 14 (Fig. 2b). The electron temperature on June 17 as measured by Langmuir probe on the same space-craft was about $3,200^{\circ} \mathrm{K}$. The corresponding value on June 14 was about $4,000^{\circ} \mathrm{K}$ (Brace, private communication). The decrease in $T_{e}$ during a magnetic storm seems to be the characteristics of the topside ionosphere at low latitudes particularly during the day time (REDDy et al., 1967).

Unfortunately, we do not have data on neutral composition and temperatures for either September or June storm. However, recent measurements have revealed that during magnetic storms, the major perturbations in the neutral atmosphere are generally confined to high and mid-latitudes. The neutral composition and temperature do not change significantly at low latitudes except during a major magnetic disturbance (CHANDRA and SPENCER, 1976; THUILLIER et al., 1976). The neutral temperature measured by the Fabry-Perot Interferometer on board the OGO-6 satellite shows that the average increase in exospheric temperature per unit increase in $K_{p}\left(\Delta T / \Delta K_{p}\right)$ is $50.5^{\circ} \mathrm{K}$ at $80^{\circ}$ latitude and $1.5^{\circ} \mathrm{K}$ at the equator. The values of $\Delta T / \Delta K_{p}$ at 60,40 and $20^{\circ}$ latitudes are respec- 
tively $39.4,22.3$ and $7.4^{\circ} \mathrm{K}$ (Thullier et al., 1976). This would indicate that during the September storm $\left(K_{p}=4\right)$, the increase at low latitudes would be about $30^{\circ} \mathrm{K}$ and in the case of June storm $\left(K_{p}=7^{+}\right)$it would be $50^{\circ} \mathrm{K}$. The effects of the compositional and related temperature changes have been estimated quantitatively by CHANDRA and HERMAN (1969). They have shown that a $50 \%$ decrease in the $\mathrm{O} / \mathrm{N}_{2}$ ratio at $100 \mathrm{~km}$ will bring in a change of about $200^{\circ} \mathrm{K}$ in the exospheric temperature and an increase in electron density by a factor of 2 at $1,000 \mathrm{~km}$. Hence a change of $30-50^{\circ} \mathrm{K}$ in exospheric temperature would bring in a change much smaller than a factor of 2 in the electron density.

The most plausible explanation for the storm related increase in the oxygen ion density at low latitudes can be given in terms of the vertical movement of

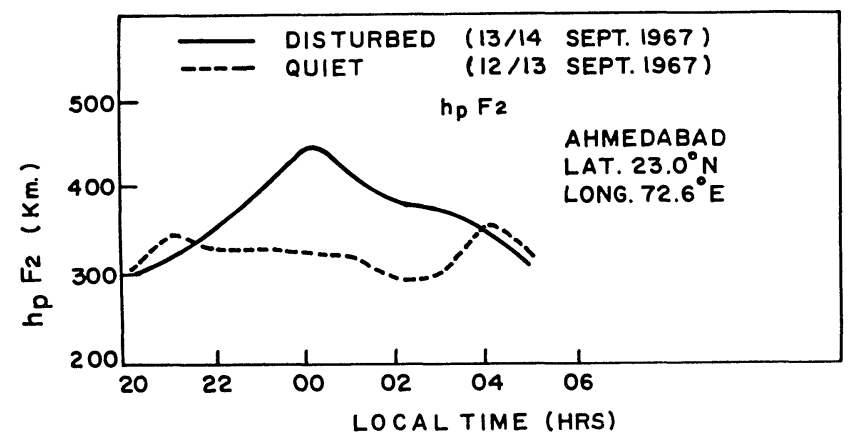

Fig. 3a. $h_{p} F_{2}$ variation for Ahmedabad for 12 and 13 Spet. 1967.

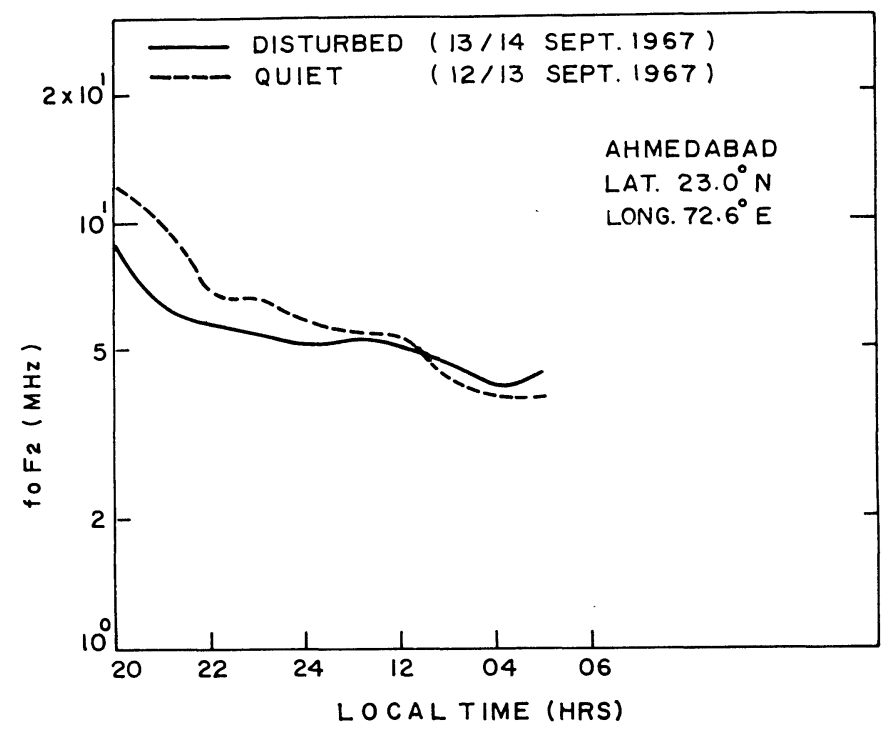

Fig. 3b. $f_{0} F_{2}$ variation for Ahmedabad for 12 and 13 Sept. 1967. 
ionization caused by a combination of neutral wind and electric field. The increase in $\mathrm{O}^{+}$density (Figs. $1 \mathrm{~b}$ and $2 \mathrm{~b}$ ) can arise due to flux from below $(F$ region) or from above (protonosphere). If there is a downward flux from the protonosphere it is expected that the $\mathrm{H}^{+}$density should be enhanced since that is the major ion at the time and altitude of observation. As the observations show either a decrease or no change in the $\mathrm{H}^{+}$density the explanation in terms of downward flux from the protonosphere does not seem plausible. Then it appears that the upward flux is the only source for increased $\mathrm{O}^{+}$density; this

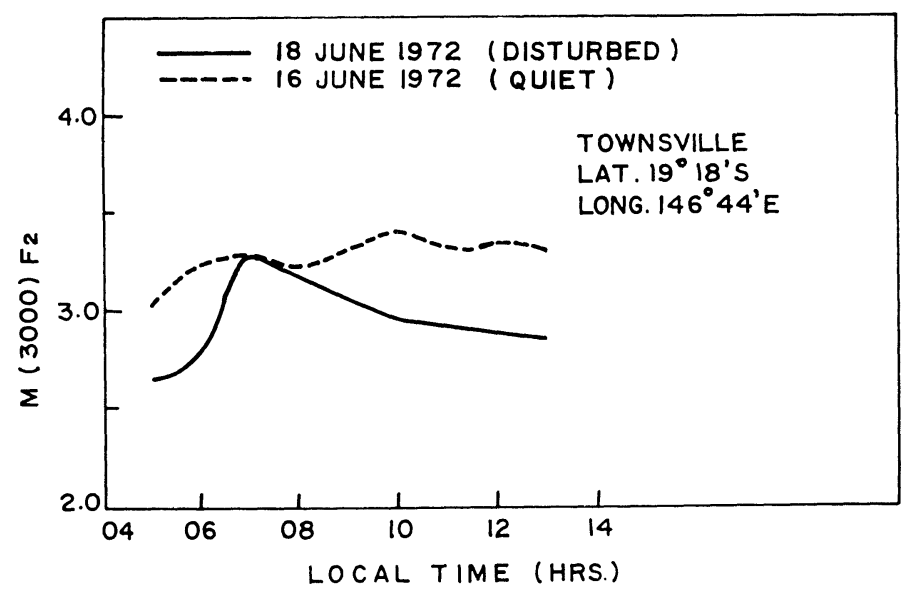

Fig. 4a. $\quad M(3,000) F_{2}$ variation for Townsville for 16 and 18 June 1972.

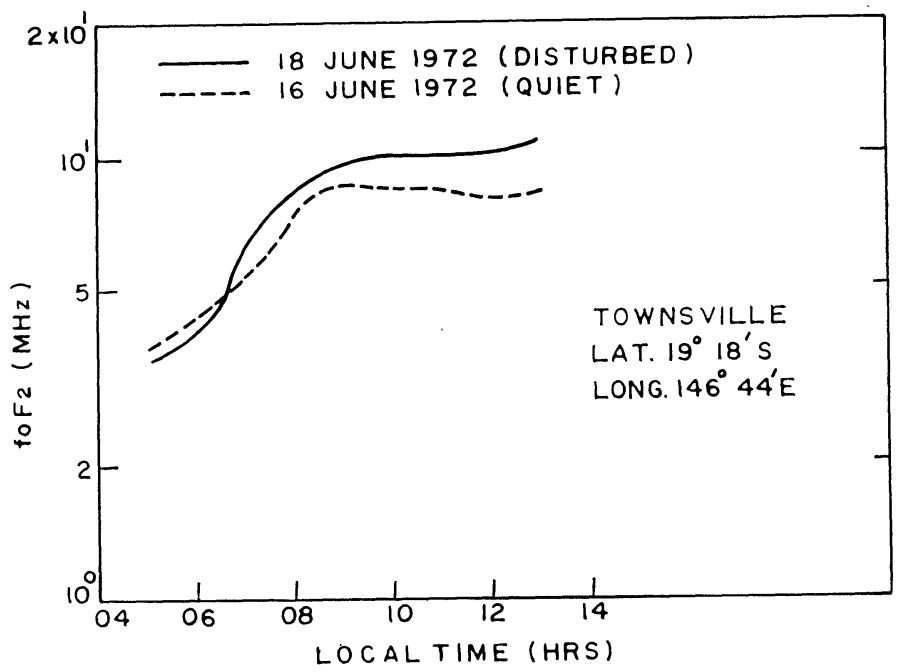

Fig. 4b. $f_{0} F_{2}$ variation for Townsville for 16 and 18 June 1972. 
is particularly the case for night time storm observations. With a view to find further evidence for the upward lifting, we have examined the $h_{m} F_{2}$ and $f_{0} F_{2}$ variations of ionospheric stations in the respective regions.

Figures $3 \mathrm{a}$ and $3 \mathrm{~b}$ show the variation of $h_{p} F_{2}$ (height of maximum electron density based on a parabolic approximation of the layer) and $f_{0} F_{2}$ for Ahmedabad $\left(23^{\circ} \mathrm{N} ; 72.5^{\circ} \mathrm{E}\right)$ which is nearer to the $60^{\circ} \mathrm{E}$ longitude zone for which satellite data were shown earlier in Fig. 1. Figure 3a shows clearly that the layer has moved up by about $100 \mathrm{~km}$ on the storm night. Figure $3 \mathrm{~b}$ shows that the difference in $f_{0} F_{2}$ at $01-02 \mathrm{hr} L T$ between quiet and storm nights is not significant. However, if we take into account the premidnight values, it shows an increasing trend at $01-02 \mathrm{hr} L T$. Both these results and in particular, $h_{p} F_{2}$ variations indicate that large upward drifts are occurring during the period of the satellite observations on the storm night.

Figures $4 \mathrm{a}$ and $4 \mathrm{~b}$ show the variation of $M(3,000) F_{2}$ (inversely related to the height of the peak of the $F_{2}$-layer) and $f_{0} F_{2}$ for Townsville $\left(19^{\circ} 18^{\prime} \mathrm{S}, 146^{\circ} 44^{\prime} \mathrm{E}\right)$ which is nearer to the $160^{\circ} \mathrm{E}$ longitude zone for which satellite data were shown earlier in Fig. 2. Using the relation between $h_{m} F_{2}$ and $M(3,000) F_{2}$ as given by ShImAZaKi (1955), it can be inferred for Fig. 4a that at $09 \mathrm{hr} L T$ the layer has moved up by about $30 \mathrm{~km}$ and at $10 \mathrm{hr} L T$ the movement of the layer is by about $70 \mathrm{~km}$ on the storm day. Figure $4 \mathrm{~b}$ shows an increasing trend in $f_{0} F_{2}$ from $07 \mathrm{hr}$ onwards giving a general support to the assumption that upward drifts were occurring at low latitudes during the June storm.

\section{Concluding Remarks}

In this paper, we have discussed some of the implications of the changes in ion composition observed at low latitudes during magnetic storms. The observed changes are most probably due to vertical movements which also give rise to positive storms. At low latitudes, the vertical motion seems to be the major factor in controlling the ionospheric behavior. The changes in neutral composition in this region are relatively of minor consequence except during severe disturbances.

We sincerely thank L.H. Brace for providing the electron temperature data for the June storm.

\section{REFERENCES}

Bauer, S.J. and B.V. Krishnamurthy, Behaviour of the topside ionosphere during a great magnetic storm, Planet. Space Sci., 16, 653-663, 1968.

Blamont, J.E. and J.M. Luton, Geomagnetic effects on the neutral temperature of the $F$-region during the magnetic storm of September 1969, J. Geophys. Res., 77, 3534-3556, 1972. 
Chandra, S. and J.R. Herman, F-region ionization and heating during magnetic storms, Planet. Space Sci., 17, 841-851, 1969.

Chandra, S. and N.W. Spencer, Thermospheric storms and related ionospheric effects, $J$. Geophys. Res., 81, 5018-5026, 1976.

Chandra, S., E.J. Maier, B.E. Troy, Jr., and B.C.N. Rao, Subauroral red arcs and associated ionospheric phenomena, J. Geophys. Res., 76, 920-925, 1971.

Evans, J.V., Mid latitude ionospheric temperatures during three magnetic storms in 1965, $J$. Geophys. Res., 75, 4803-4813, 1970.

Evans, J.V., The causes of storm time increases of the F-layer at mid latitudes, J. Atmos. Terr. Phys., 35, 593-616, 1973.

JaCChia, L.G., J. Slowey, and F. Verniani, Geomagnetic perturbations and upper ionosphere heating, J. Geophys. Res., 79, 1423-1434, 1967.

Maier, E.J., S. Chandra, J.H. Hoffman, G.G. Shepherd, and J.H. Whitterker, The SAR arc event observed during the Dec. 1971 magnetic storm, J. Geophys. Res., 80, 4591-4597, 1975.

Matsushita, S., Ionospheric Variations during geomagnetic storms, Proc. Int. Conf. Ionos., Inst. Phys. Soc., London 120, 1963.

Obay ashi, T., Morphology of storms in the ionosphere, in Research in Geophysics, edited by $\mathrm{H}$. Odishaw, Vol. 1, pp. 335, M.I.T. Press, New York, 1964.

Prolss, G.W. and U. Von ZAHN, ESRO 4 gas analyzer results, 2 direct measurements of changes in the neutral composition during an ionospheric storms, J. Geophys. Res., 79, 2535-2539, 1974.

REDDY, B.M., L.H. BRACE, and J.A. FindLEY, The ionosphere at $640 \mathrm{~km}$ on quiet and disturbed days, J. Geophys. Res., 72, 2709-2727, 1967.

Richmond, A.D. and S. Matsushita, Thermospheric response to a magnetic sub-storm, $J$. Geophys. Res., 80, 2839-2850, 1975.

Rishbeth, H., On explaining the behaviour of the ionospheric F-region, Rev. Geophys., 6, 33$71,1968$.

Rishbeth, H., F-region storms and thermospheric circulation, J. Atmos. Terr. Phys., 37, 10551064, 1975.

Ruster, R. and J.W. KING, Negative ionospheric storms caused by thermospheric winds, $J$. Atmos. Terr. Phys., 38, 593-598, 1976.

ShimazAKI, T., World-wide daily variations in the height of the maximum electron density of the ionospheric $F_{2}$ layer, J.R.R.L., 2, 85-97, 1955.

Somayajulu, Y.V., Changes in the F-region during magnetic storms, J. Geophys. Res., 68, 1899-1922, 1963.

Taeush, D.R., G.R. Carignan, and C.A. Reber, Neutral composition variation above $400 \mathrm{~km}$ during a magnetic storm, J. Geophys. Res., 76, 8318-8325, 1971.

Thuiller G., J.L. Falin, and C. Watchtel, Experimental global model of the exospheric temperature based on measurements from the Fabry-Perot interferometer on board the OGO-6 satellite, COSPAR, 8-19 June, 1976. 